\title{
Liver Function Test
}

National Cancer Institute

\section{Source}

National Cancer Institute. Liver Function Test. NCI Thesaurus. Code C74954.

The quantitative measurement of liver enzymes in the blood, which is useful in assessing the functional state of a patient's liver. Liver function tests include the measurement of albumin, alanine transaminase, aspartate transaminase, alkaline phosphatase, bilirubin, and gamma glutamyl transferase. 